\title{
Finite Element Models to Simulate Lightweight Rockfall Protection Structures
}

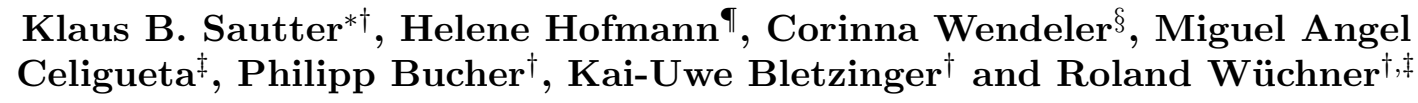

$\dagger$ Technical University of Munich (TUM), Chair of Structural Analysis Arcisstr. 21, D-80333 München, Germany

e-mail: klaus.sautter@tum.de, web page: www.st.bgu.tum.de

¥Centre Internacional de Mètodes Numèrics en Enginyeria (CIMNE)

Campus Nord UPC, 08034 Barcelona, Spain

ฯ Geobrugg AG, Aachstr. 11, Romanshorn 8590, Switzerland

$\S$ Appenzell Ausserrhoden, Department of Construction and Economics, Civil Engineering

Office, Hydraulic Engineering, Kasernenstr. 17A, Herisau 9102, Switzerland

Rockfall protection systems are highly flexible structures that can absorb large amounts of energy. Compared to rigid protection structures, these structures undergo large deformations upon impact and thus result in lower braking accelerations. This leads to an effective transfer of the load. Previous works such as e.g. [1] have shown that the partly highly complicated real ring structures and rope constructions can be represented by simplified numerical structural

models if the global behavior of the protective structure and the impacting objects is of interest. We discuss the appropriate modeling of the protective structures, slipping edge ropes, and plasticizing brake elements using the finite element method (FEM) in this work. The realization of the impact simulation by coupling particle methods and the FEM is briefly discussed and can be found in $[1,2,3]$ among others.

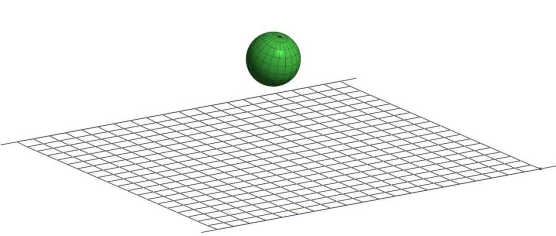

(a)

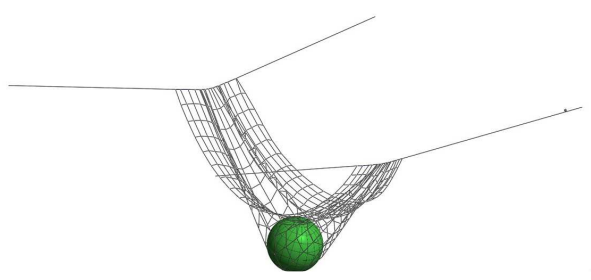

(b)

Figure 1: Impact simulation on cable net with moving edge nodes, adapted from [2, 3]. 1a) Before impact. 1b) After impact.

\section{REFERENCES}

[1] K. B. Sautter, H. Hofmann, C. Wendeler, R. Wüchner, and K.-U. Bletzinger, Influence of the refinement of DE-Clusters with regard to the numerical analysis of rock-fall experiments, Computational Particle Mechanics, (2021).

[2] K. B. Sautter, T. Teschemacher, M. A. Celigueta, P. Bucher, K.-U. Bletzinger, and R. Wüchner, Partitioned strong coupling of discrete elements with large deformation structural finite elements to model impact on highly flexible tension structures, Advances in Civil Engineering, (2020)

[3] C. Wendeler, K. B. Sautter, P. Bucher, K.-U. Bletzinger, and R. Wüchner, Modellierungsaspekte und gekoppelte DEM-FEM Simulationen zur Untersuchung hochflexibler Steinschlagschutznetze, Berichte der Fachtagung Baustatik - Baupraxis 14, (2020) 